\title{
A Systematic Literature Review on the Role of Mentoring and Feedback in Improvement of Teaching Practicum
}

\author{
*Tahira Kalsoom: Assistant Professor, R \& E D Lahore College for Women University, Lahore \\ **Dr. Victoria Showunmi: UCL Institute of Education UK \\ ***Iram Ibrar: MS Scholar
}

\begin{abstract}
This study explores that feedback becomes effective when it is purposeful. Feedback should provide in such a way that the prospective teachers must reach the specific purpose and learning goal behind the practicum experience i.e. the change in teaching behavior and to become a more professional teacher. If provision of feedback does not fulfill the purpose behind the process then it is just the wastage of time. Systematic literature review was used as a research methodology and detailed literature was cited to see all aspects of feedback and mentoring to improve practicum. Feedback becomes effective only when it provides information to the prospective teachers either they are performing their tasks to achieve their learning goals properly or they may need some correction. It is evident from the literature that there is a significant difference in the role of mentor and supervisor. Mentors play the role of advisor, friend, guide and counselor while supervisors play the role a teacher, assessor and boss.
\end{abstract}

Key words: Mentoring, Feedback, Role Teaching, Practicum, Education

\section{Introduction}

It is acknowledged repeatedly by previous studies that feedback has the capacity to improve the learning process and it provides various learning opportunities to the learner. Hattie (2008) acknowledges that it is very difficult for him to understand the concept of feedback because it puts great effects on the learning and achievement of a student. Feedback is a source to inform the students about the intensity of the efforts they have to put forth to reach their desired goals. Many researchers emphasized that with the provision of adequate and accurate feedback they can produce greater learning (Bransford, Brown, \& Cocking, 2000;

\footnotetext{
*Research and Evaluation Department Lahore College for Women University, Lahore Pakistan.

Email: tahira.kalsoom@yahoo.com

**UCL Institute of Education UK. Email: v.showunmi@ioe.ac.uk

*** (MS Scholar) Lahore College for Women University, Lahore Pakistan. Email: iram.ibrar15@gmail.com
} 
Hattie, 2008; Marzano, Pickering, \& Pollock, 2001). In the modern era, instead of using behaviorist theories to explain the role of feedback, most of the educational researchers, thinkers and theorists focus on the kind and the context of feedback given to the students. Most of the studies emphasize on the role of the student in the process of feedback. Recently, many researchers have conducted studies to find out the role of feedback and its impact on the student's learning in different settings. Stuart (2004) conducted an exploratory study in Singapore to find out the impact of immediate feedback on student performance. Vollmeyer and Rheinberg (2005) conducted an experimental study about the surprising effect of feedback on learning. Hatziapostolou and Paraskakis (2010) conducted an online study to find out the enhancing impact of formative feedback on student learning through an online feedback system. They tried to improve the quality of feedback and awareness about it through their study.

\section{Statement of the Problem}

Teaching practicum is a kind of teacher training program in which prospective teachers put the theory they learned during course work, into practice. They gain insight about their teaching practice through reflection and make improvements where needed under the supervision of an expert or a mentor. For the enhancement of students' performance and achievement, there is a great need to improve the teaching practices among prospective teachers by looking closely whether the feedback being provided to the students is effective or not.

\section{Objectives of the Study}

The study aims to:

1. Explore literary evidence regarding feedback during teaching practicum.

2. Identify the importance of feedback and supervision for the improvement of teaching practicum.

\section{Research Questions}

1. What is the literary evidence regarding feedback during teaching practicum?

2. What is the importance of feedback and supervision for the improvement of teaching practicum?

\section{Method and Procedure of the Study}

The study is descriptive in nature and the technique of systematic literature review is used to describe the topic understudy from the available literature by using different resources. 
According to Baumeister and Leary (1997) "A systematic review is a piece of research in its own right and, by its nature, is able to address much broader questions than a single empirical study ever can e.g. uncovering connections among many empirical findings."

\section{Historical View of Feedback}

The initial studies and theories established by experts as a result of many experiments and a lot of researches about the concept of feedback are almost 100 years old. Many researchers started work on this concept and provided the solid background for the effectiveness of feedback. Basically, the concept of feedback came out from the Thorndike's (1913) psychological perspective or a school of thought called behaviorism. This theory illustrates that feedback remains effective if it is considered as positive reinforcement whereas feedback does not remain effective if it is considered as punishment or negative reinforcement.

In the literature, many researchers conducted different studies to elaborate the concept and characteristics of effective feedback (Johnston, 2004) did a meta-analysis of studies regarding feedback. The findings of his meta-analysis showed the effectiveness of feedback depend on the nature and type of the feedback being provided to the students. Some scholars have conducted the studies to describe the things which make one type of feedback effective and another type ineffective (Butler \& Winne, 1995). After reviewing others works Hattie and Timperley (2007) propose a model of feedback that describes four distinguished levels:

(1) Feedback about the task performed by student

(2) Feedback about the processing of the task

(3) Feedback about self-regulation

(4) Feedback about the student.

\section{What is Mentoring?}

Numerous definitions are found in the literature to describe the concept of mentoring. Previous studies (Patrick, 2013) highlighted that mentoring is an interpersonal relationship in which mentor plays the role of an experienced person who is responsible to provide the professional knowledge and skills to his/her mentee. Review of literature depicts that mentoring become effective and valuable when it includes the three elements i.e. relationship between mentor and mentee, process of professional development and context in which mentoring occurs. According to Lai (2005) in terms of dimensions there are three components which have very great impact on mentoring relationship i.e.

- Relational, 
- Developmental

- Contextual

Mentoring can be provided in different situations with different ways or in different context according to the nature and purpose of activity (Aspfors \& Fransson, 2015). There are number of styles and formats in which mentoring can be practiced. On the basis of previous studies, Kemmis, Heikkinen, Fransson, Aspfors, and Edwards-Groves, (2014) determine in their study that supervision; support and collaborative self-development are three types of mentoring. It is also described by Myers and Anderson (2012) that in different perspectives, mentoring can be provided in different manners.

According to Walkington (2005), practicum is also known as a professional and field experience. It is specific times period in which prospective teachers are engaged in teaching practice and are involved in learning the pedagogic skills, attitudes and beliefs. It is helpful to raise the confidence level of prospective teachers and provide them opportunities to grow professionally through the process of reflection. In the field of teaching practicum mentoring serves as a back bone for the professional growth of student teachers. In the view of Kaasila and Lauriala (2010) during practicum, mentoring remains beneficial for all stake holders in the way it raise the confidence and perfection level of mentor by providing assistance to the mentee and enhance the personal and professional development of mentees on the other hand.

Many studies recognized (Hagger \& McIntyre, 2006) that collaboration between mentor and prospective teachers is fundamental for the development of professional knowledge and skills of prospective teachers during practicum. During practicum, mentors and prospective teachers collaborate with each other and mentors provide valuable feedback to the prospective teachers about their teaching performance and on the other hand prospective teacher reflect upon and remove their mistakes and strengthen their pedagogic skills. As stated by $\mathrm{He}$ (2009) Mentoring is a collaborative exercise and mutual communication between mentor and mentee.

Communication failure among them creates conflicts between the beliefs and practice of prospective teachers and may lead the discrepancy among them. Mentoring builds a bridge between mentors and their mentees as they can remove the gap of knowledge through mutual understanding and sharing of ideas in the classroom environment.

Numbers of factors are involved in the quality of mentoring. According to Damar (2013) mentor's training, time, energy and enthusiasm is very essential for quality mentoring. However during practicum quality mentoring from expert teachers or mentors puts a great 
influence on the teaching practice of prospective teachers. Some researchers also emphasize on the importance of mentors' interpersonal skills and communication skills for the effective mentoring. (Hudson \&Nguyen, 2008; Bonilla \& Méndez Rivera, 2008) emphasize that mentors should have the qualities of listening the problems of prospective teachers, stimulating motivation, sharing of ideas with prospective teachers, influencing, counseling and being trustworthy to help the prospective teachers in solving their specific problems relating to their pedagogy.

Effective mentoring during practicum is not only the process of observing and assessing the prospective teachers' performance. It also provides the opportunities of learning to teach within the classroom settings to the prospective teachers. It is mentoring through which prospective teachers become able to know what they did during their practice and what should they do next to improve their quality. Mentor's feedback leads them to reflection and self-awareness. As illustrated by Smith (2007) during practicum the basic role of mentoring is the provision of feedback to improve the pedagogy of prospective teachers through stimulating their reflection.

\section{Principles of Effective Feedback during Practicum}

To make the feedback much effective and valuable for the professional growth and development of prospective teachers, mentors should follow the underlying principles of provision of feedback:

\section{Purposeful}

Feedback becomes effective when it is purposeful. Feedback should be provided in such a way that the prospective teachers must reach the specific purpose and learning goal of practicum experience i.e. the change in teaching behavior and to become a more professional teacher. If provision of feedback does not fulfill the purpose behind the process then it is just the wastage of time. Feedback becomes effective only when it provides information to the prospective teachers either they are performing their tasks to achieve their learning goals properly or they may need some correction. According to Nesbitt, Pitcher, James, Sturrock, and Griffin (2014) generic phrases are not specific and does not provide valuable information to the student for the improvement of their performance. These terms does not provide effective feedback to the students to fulfill the gap between their actual and desired performance (Wiggins, 2012). 


\section{Timely}

A great problem in education, however, is untimely feedback (Wiggins, 2012). Mentors should provide specific feedback to the prospective teachers' right after their performance. As much as long delay occurs in the provision of feedback, as a human being, it is not possible for a mentor to remember all important points on which he/she has to provide feedback to the student teachers.

Murdoch Eaton and Sargeant (2012) said that immediate feedback is important to achieve the desired learning outcomes about the development of verbal and motor skills and delayed feedback may be important for the development of problem solving skills and meta cognitive behaviors. But the delayed feedback also serves as a source of de-motivation among learners.

\section{Actual, Definite and Clear}

Feedback should be actual and definite in the sense that it addresses the real weakness or may be the real weakness of prospective teachers. Moreno (2004) said that to prevent the learners from being confused, clear and definite feedback should be provided to the learners about the success and failure of their performance. Mentor and peer should use clear words while providing feedback so that the process may remain unambiguous and provide clear information to the prospective teachers about their performance. Effective feedback should be so actual, definite and clear that prospective teacher can learn from it and make outstanding improvements in their teaching behavior. According to Hattie (2011) learners become confused and misunderstood when unclear feedback is being provided to them.

\section{Actionable}

Feedback should be clear and concise. Sometimes ambiguous statements are used by mentors while providing feedback to the prospective teachers. Actionable feedback provides clear direction to the learners that what steps should be taken to move forward (Chimhenga, 2016). Actionable feedback is objective in nature and provides information to the prospective teachers about what is the real problem and how they can solve it. Actionable and specific feedback prevents the prospective teachers from misinterpretation of the feedback.

\section{Consistent}

Feedback should be consistent otherwise it will fail to make effective influence on the prospective teacher's performance during practicum (Chimhenga, 2016) Mentors should keep in mind that the information they provide must be unwavering and accurate otherwise student 
teachers will not be able to perform well. Inconsistent feedback can damage the practicum experience of prospective teachers (Copland, 2010)

\section{Benefits of Feedback}

There are a numerous benefits of feedback as acknowledged in the previous researches. Feedback is very helpful for students to improve their learning by encouraging them. In the opinion of Cornu, (2005) provision of formative feedback has the power to improve the students learning. Feedback provides support to the students and is important to raise the learning. According to Shepard (2000) Feedback is a persistent part of the instructional process because it provides support to the students and raises their learning. Feedback proves very beneficial to improve the knowledge, skills and behavior of the students. Hattie (2011) said that the impact of feedback on the students' behavior is very strong. Effective feedback provides information about the gap between actual and desired performance of the learners and motivates them to achieve the desired outcomes. Feedback promotes the students learning by informing them about their progress and needs for improvements (Shepard, 2000).

\section{Importance and Impact of Feedback}

Sedumedi and Mundalamo, (2014) conducted a theoretical study to explain the feedback and its usefulness in the managerial context. He wrote that three conditions are very important to make the feedback effective i.e.

- Data must be available about the desired level of the focal system parameter,

- Data should be on the actual level of the same parameter

- Both forms of data should be compared through a proper system (Shepard, 2000).

By definition, absence of any one or more of the above three conditions will render the process of feedback to be ineffective. He also described that any information can only be referred as feedback if it used to remove the gap between the actual and desired performance.

Mazur (2009) at Harvard did a practice in which he gave problems to his 200 introductory physics students and advise them to make group discussions after thinking individually he discussed in groups and provided reflections on the participation of each students. In this practice he tried to find out the effectiveness of reflection which occurs due to the provision of feedback. On the basis of this practice, he said that provision of frequent 
and continuous feedback can enhance the conceptual understanding and problem-solving skills of the students.

Many researchers acknowledged that feedback plays a fundamental role in different fields of life. Teaching practicum plays a crucial role for the training and professional development of prospective teachers. Practicum experience provides skills, knowledge and professional competence to the prospective teachers. Numerous factors are involved in making the practicum experience successful for prospective teachers. Quality feedback is one of the most significant and prominent factor. As said by White (2007) success of practicum also depends upon the type of feedback being provided to prospective teachers.

It is also needed to find out the perceptions of prospective teachers whether they understand the importance of feedback or not. For this purpose Fawzi and Alddabous (2019) conducted a study based on mixed method research design to identify the perceptions of prospective teachers about the quality of feedback they gain by their mentors during their teaching practicum and their familiarity with the concepts and types of feedback. Participants of this study revealed that the feedback they received by their mentors was very valuable for their professional development. Their mentors provided very clear, accurate and helpful feedback to them to improve their teaching practice.

Findings of Fawzi and Alddabous's (2019) study also revealed that immediate, oral and written feedback was preferred by the prospective teachers. Feedback should be based on graded rubrics; mentors should focus on their performance rather than criticizing their mistakes while providing feedback. It is illustrated in this study that prospective teachers perceive quality feedback very important for the improvement of their teaching practice and profession competence.

\section{Role of Mentor and Mentee}

Ambrosetti and Dekkers (2010) review the literature about the 'Interconnectedness of the Roles of Mentors and Mentees in Pre-service'. The aim of their study was to find out the role of mentors and the role of pre service teachers to make the experience of teaching practicum successful. By reviewing the literature they elaborate that mentors consider their role as providing support for mentees, observer, counselor, and provider of feedback, modeling, equal partner and instructor (Hudson, 2013). Their study exhibits that the perspective of mentees or prospective teachers about the role of mentor is very similar to the perspective of mentors such as support provider, role model, collegial partner and effective communicator (Mukeredzi,., \& Mandrona, 2013). 
Very limited research is done about the role of mentee to make the mentoring relationship effective while they play a crucial role in the success of mentoring experience. Ambrosetti and Dekkers (2010) said that more research is needed to clarify the role of mentee in the process of mentoring. They describe the interconnected role of mentor and mentee in the process of mentoring in the way that if mentor plays the role of supporter then the mentees become motivated and more responsible to perform their tasks effectively. If mentor serves as a role model then mentees become a good observer and reflector. If mentor plays the role of collaborator then mentee learns to work with others collaboratively.

\section{Difference between Mentoring and Supervision during Practicum}

Mentoring and supervision are slightly different terms but both terms play a vital role in the field of practicum. Mentoring and supervision are different just like feedback and assessment are different from each other. It is easier to say that mentoring relates to the provision of feedback whereas supervision relates to the procedure of assessment. As said by Walkington (2005) in her study, that there is a significant difference in between mentoring and supervision. She describes that, supervisors are involved in making judgment of the prospective teachers' performance while mentors are not involved in it, so the procedure of assessment belongs to the supervision.

Different researchers presented their opinion on the process of mentoring during practicum and describe mentors' responsibilities accordingly. Some researchers emphasize that mentors should act as a role model, supporter, observer, advisor, counselor, planner of teaching experiences, and professional peer. It is evident from the literature that there is a significant difference in the role of mentor and supervisor. According to Bray and Nettleton (2007), mentors play the role of advisor, friend, guide and counselor while supervisors play the role of a teacher, assessor and boss.

The term supervision is an old terminology used in past to provide learning essentials to the prospective teachers by an experienced person. On the other hand mentoring is a new terminology used in this field from a few decades. Supervision and the process of socialization are closely related to each other. Their association is obvious because socialization is a process in which teaching and learning occurs side by side for the sake to act just according to the particular culture and environment of the society. Burgess and Mellis (2015) describes that an expert supervisors play the role to shape the prospective teachers just according to specific environment of school in which they are practicing teaching. In the view of Brandt (2008), Mentoring is more functional in comparison to supervision because it 
includes the development of interpersonal relationships, psychosocial development and more professionalism along with the activities of socialization.

\section{Guidelines for the Provision of Effective Feedback}

Following guidelines are drawn from the review of literature for teachers and mentors about the provision of effective feedback to make the improvement of learning process:

\section{Provide Written Feedback to the Students}

Written feedback is long lasting; it provides the chance of improvement by revisiting the errors. Written feedback is more effective and students learn more from it because oral feedback skips from mind with the passage of time. Bruning, Schraw, Norby \& Ronning, (2004) said that written feedback is more useful and students become motivated to perform their task very well.

\section{Stop the Use of Red Ink While Writing Comments in Written Feedback}

Many students identify that they feel bad when their teachers notify their mistakes with red ink on their notebooks. It is acknowledged in literature that the color red has negative connotations. The result of a study identify that $10 \%$ scores of a test were drop due to the use of red ink (Science Netlinks, 2007).

\section{Provide Second Chance for the Improvement}

Provide the opportunity to students to perform their task again for the sake of improvement and learning. Through this students will able to practice the teacher's suggestions and gain appreciation on improved performance. Provision of second chance means to appreciate the learning process (Shute, 2008).

\section{References}

Ambrosetti, A., \& Dekkers, J. (2010). The interconnectedness of the roles of mentors and mentees in pre-service teacher education mentoring relationships .Australian journal of teacher education, 35(6), 3.

Aspfors, J., \& Fransson, G. (2015). Research on mentor education for mentors of newly qualified teachers: A qualitative meta-synthesis. Teaching and teacher education, 48, 75-86.http://dx.doi.org/10.1016/j.tate.2015.02.004

Baumeister, R. F., \& Leary, M. R. (1997). Writing narrative literature reviews. Review of General Psychology, 3, 311-320.

Bonilla, S. X., \& Méndez Rivera, P. (2008). Mentoring in pre-service teaching: from reflection on practice to a didactic proposal. Actualidades pedagógicas, 1(52), 79-90.

Bourke, J. M. (2001). The role of the TP TESL Supervisor. Journal of education for Teaching, 27(1), 63-73. 
Brandt, C. (2008). Integrating feedback and reflection in teacher preparation.ELT journal, 62 (1), 37-46.

Bransford, J. D., Brown, A. L., \& Cocking, R. R. (2000). How people learn (Vol. 11). Washington, DC: National academy press.

Bray, L., \& Nettleton, P. (2007). Assessor or mentor? Role confusion in professional education. Nurse education today, 27(8), 848-855.

Bruning, R. H., Schraw, G. J., \& Ronning, R. R. (2004).Cognitive psychology and instruction. Prentice-Hall, Inc., One Lake Street, Upper Saddle River, NJ 07458.

Burgess, A., \& Mellis, C. (2015). Feedback and assessment for clinical placements: achieving the right balance. Advances in medical education and practice, 6, 373-381

Butler, B. M., \& Cuenca, A. (2012).Conceptualizing the roles of mentor teachers during student teaching. Action in Teacher education, 34(4), 296-308.

Butler, D. L., \& Winne, P. H. (1995). Feedback and self-regulated learning: A theoretical synthesis. Review of educational research, 65(3), 245-281.

Chimhenga, D. (2016). Student-Teachers' perspectives of mentoring practices during their teaching practicum in Zimbabwean schools. Global Journal of Advanced Research, $3(5), 405-410$.

Copland, F. (2010). Causes of tension in post-observation feedback in pre-service teacher training: An alternative view. Teaching and Teacher Education, 26(3), 466-472.

Cornu, R. L. (2005). Peer mentoring: Engaging pre-service teachers in mentoring one another. Mentoring \& Tutoring: Partnership in Learning, 13(3), 355-366.

Damar, E. A., \& Salı, P. (2013).ELT teacher trainees' reflective feedback to their cooperating teachers. Journal of Educational and Social Research, 3(7), 235. http://dx.doi.org/10.5901/jesr.2013.v3n7p235

Fawzi, H., \& Alddabous, S. (2019). Pre-service teachers' perceptions and preferences of feedback process. International Journal of Education, Learning and Development. $7(1), 36-47$

Hagger, H., \& McIntyre, D. (2006).Learning teaching from teachers: Realizing the potential of school-based teacher education. McGraw-Hill Education (UK).

Hattie, J. (2008). Visible learning: A synthesis of over 800 meta-analyses relating to achievement. routledge.

Hattie, J. (2011). Feedback in schools. In R. Sutton, M.J. Hornsey, \& K.M. Douglas (Eds.), Feedback: The communication of praise, criticism, and advice. New York, NY: Peter Lang Publishing.

Hattie, J., \& Timperley, H. (2007). The power of feedback. Review of educational research, 77(1), 81-112. 
Hatziapostolou, T., \& Paraskakis, I. (2010).Enhancing the impact of formative feedback on student learning through an online feedback system. Electronic Journal of e-Learning, 8(2), 111-122.www.ejel.org

He, Y. (2009). Strength- based mentoring in pre- service teacher education: a literature review. Mentoring \& Tutoring: Partnership in Learning, 17(3), 263-275. https://doi.org/10.1111/j.1746-1561.2006.00132.x

Hudson, P. (2013). Feedback consistencies and inconsistencies: eight mentors' observations on one pre-service teacher's lesson. European Journal of Teacher Education, 37(1), 63-73. http://dx.doi.org/10.1080/02619768.2013.801075

Kaasila, R., \& Lauriala, A. (2010).Towards a collaborative, interactionist model of teacher change. Teaching and Teacher Education, 26(4), 854-862.

Kemmis, S., Heikkinen, H. L., Fransson, G., Aspfors, J., \& Edwards-Groves, C. (2014). Mentoring of new teachers as a contested practice: Supervision, support and collaborative self-development. Teaching and teacher education, 43, 154-164. http://dx.doi.org/10.1016/j.tate.2014.07.001

Lai, E. (2005). Mentoring for in-service teachers in a distance teacher education programme: views of mentors, mentees and university teachers. In Australian Association for Research in Education International Education Research Conference, Parramatta.

Marzano, R. J., Pickering, D., \& Pollock, J. E. (2001).Classroom instruction that works: Research-based strategies for increasing student achievement. Ascd.

Mazur, E. (2009). Farewell, lecture? Science, 323(5910), 50-51.

Moreno, R. (2004). Decreasing cognitive load for novice students: Effects of explanatory versus corrective feedback in discovery-based multimedia. Instructional science, 32(1-2), 99-113.doi:10.1023/B:TRUC.0000021811.66966.1d

Mukeredzi, T. G., \& Mandrona, A. R. (2013). The journey to becoming professionals: Student teachers' experiences of teaching practice in a rural South African context. International Journal of Educational Research, 62, 141-151.

Murdoch Eaton, D., \& Sargeant, J. (2012).Maturational differences in undergraduate medical students' perceptions about feedback. Medical education, 46(7), 711-721.

Myers, S. D., \& Anderson, C. W. (2012). Mentoring in Teacher Education. Rotterdam: Sense Publishers.

Nesbitt, A., Pitcher, A., James, L., Sturrock, A., \& Griffin, A. (2014).Written feedback on supervised learning events. The clinical teacher, 11(4), 279-283.

Patrick, R. (2013). "Don't rock the boat": Conflicting mentor and pre-service teacher narratives of professional experience. The Australian educational researcher, 40(2), 207-226.

Science NetLinks. (2007). Seeing red. Retrieved from http://www.sciencenetlinks.com /sci_update.php?DocID=323 
Sedumedi, T. D., \& Mundalamo, F. J. (2014).School mentors' assessment of science student teachers during teaching practicum. Mediterranean Journal of Social Sciences, 5(20), 1511.

Shepard, L. A. (2000). The role of assessment in a learning culture. Educational researcher, 29(7), 4-14.

Smith, K. (2007). Empowering school- and university-based teacher educators as assessors: A school-university cooperation. Educational Research and Evaluation, 13(3), 279293.

Sorcinelli, M. D., \& Sorcinelli, G. (1988). Effective use of time in the classroom: An Instructor's Guide. Chicago: Northeastern University.

Stuart, I. (2004). The Impact of immediate feedback on student performance: An exploratory study in Singapore. Global perspectives on accounting education, 1(1), 1. http://digitalcommons.bryant.edu/gpae/vol1/iss1/1

Thorndike, E. L. (1913). The psychology of learning (Vol. 1).Teachers College, Columbia University.

Vollmeyer, R., \& Rheinberg, F. (2005).A surprising effect of feedback on learning. Learning and Instruction, 15(6), 589-602.

Walkington, J. (2005). Mentoring pre-service teachers in the preschool setting: Perceptions of the role. .Australian Journal of Early Childhood, 30(1), 28-35.

White, S. (2007). Investigating effective feedback practices for pre-service teacher education students on practicum. Teaching Education, 18(4), 299-311. https://doi.org/10.1080/10476210701687591

Wiggins, G. (2012). Seven keys to effective feedback. Feedback, 70(1), 10-16. 